\title{
Does gallium-citrate have yet another story to tell? Lessons relevant to the COVID-19 era
}

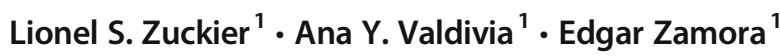 \\ Published online: 28 May 2020 \\ (C) Springer-Verlag GmbH Germany, part of Springer Nature 2020
}

The evolution of $\left[{ }^{67} \mathrm{Ga}\right] \mathrm{Ga}$-citrate as an imaging agent over the past three quarters of a century is fascinating from a historical point of view $[1,2]$. Its storied saga recalls the formative years in the rise of nuclear medicine and many of the important diagnostic roles that scintigraphy played in the provision of health care over the past seven decades. $\left[{ }^{67} \mathrm{Ga}\right] \mathrm{Ga}-$ citrate was introduced at the time when mechanisms of localization of radiopharmaceuticals were rather opaque and choice of radiopharmaceuticals often proceeded by trial and error, if not by outright serendipity. Raymond Hayes has succinctly summarized this odyssey from a first-hand perspective [1]. In the late 1940s, non-radioactive gallium metal was being considered as a coolant for use in nuclear powered naval vessels which stimulated studies on the metal's biodistribution. Utilizing the tracer principle, Dudley and coworkers determined that $\left[{ }^{72} \mathrm{Ga}\right] \mathrm{Ga}$-citrate (and ionic gallium, in general) localized to a large degree at sites of osteogenesis [3, 4]; based on these findings, in the pre-technetium imaging agent era, there was interest in developing the radiopharmaceutical into a bone imaging, and potentially therapeutic, modality [5]. Gallium-72's decay properties were eventually deemed insufficiently favorable for human use. Investigators at Oak Ridge and Bethesda subsequently turned their attention to $\left[{ }^{67} \mathrm{Ga}\right] \mathrm{Ga}-$ citrate, with its improved decay properties, but were chagrined to observe that the citrate ion of this radioisotope did not replicate the biodistribution seen with $\left[{ }^{72} \mathrm{Ga}\right] \mathrm{Ga}$-citrate; they quickly realized that the disparity arose because of variation in specific (molar) activity of the radiopharmaceutical $[6,7]$. Gallium-72, derived from reactor-production, contained

This article is part of the Topical Collection on Infection and Inflammation

Lionel S. Zuckier

LZuckier@montefiore.org

1 Division of Nuclear Medicine, Department of Radiology, Montefiore Medical Center and the Albert Einstein College of Medicine, 1695A Eastchester Road, Bronx, NY 10461, USA chemically significant amounts of non-radioactive ("carrier") gallium, while Gallium-67 was produced in a cyclotron and was "carrier free", that is without addition of non-radioactive gallium atoms. Both radioisotopic forms of gallium-citrate were deemed not useful for bone imaging and were shelved for a decade. In the 1960s, investigators at Oak Ridge rekindled their interest in gallium as a means of bone imaging (including the possibility of addition of carrier gallium as needed), in part stimulated by new availability of Gallium68. According to Hayes [1], the investigators were amazed to observe that carrier-free $\left[{ }^{67} \mathrm{Ga}\right] \mathrm{Ga}$-citrate intensely localized in lymph nodes of a patient with Hodgkin's disease [8], thereby laying the ground-work for what would subsequently become extensive use of carrier-free $\left[{ }^{67} \mathrm{Ga}\right] \mathrm{Ga}$-citrate for clinical tumor imaging [9]. It was understood that ionic gallium in the blood was bound to circulating transferrin much in the way that iron is bound. Reliance on gallium scanning for lymphoma staging would prevail for decades, only waning in the 2000s when eclipsed by the novel radiopharmaceutical (D)$2-\left[{ }^{18} \mathrm{~F}\right]$ Fluoro-deoxy-glucose $\left(\left[{ }^{18} \mathrm{~F}\right] \mathrm{FDG}\right)$, coupled with widespread availability of PET-CT cameras [10].

Another twist in the circuitous story of gallium emerged in the early 1970s, when it was serendipitously noted that $\left[{ }^{67} \mathrm{Ga}\right] \mathrm{Ga}$-citrate was not specific to tumor but also localized in sites of inflammation and infection [11-13]. The indefatigable radiopharmaceutical therefore emerged as a useful agent for infection imaging. Availability of this technique dovetailed with a surge in infectious disease coincident with emergence of the AIDS epidemic in the 1980s, which unfortunately presented much opportunity for imaging of previously rare and unusual infections such as atypical tuberculosis, and Pneumocystis jiroveci. $\left[{ }^{67} \mathrm{Ga}\right] \mathrm{Ga}$-citrate was noted to be an effective means of imaging in virtually all of the AIDSrelated tumors and infections, with the exception of Kaposi's sarcoma, where $\left[{ }^{201} \mathrm{Tl}\right]$ Thallium-chloride held sway [14]. While ${ }^{111}$ In-labeled white blood cells were also effective in imaging suppurative infections, one of the advantages of gallium in these populations was that it did not require handling 
of blood products, and imaging could be performed in patients with leukopenia [15].

One is struck when reviewing the early gallium literature on the disparity between the widespread adoption of the radiopharmaceutical and the corresponding paucity of insight into its mechanisms of action. A qualitative leap in the understanding of $\left[{ }^{67} \mathrm{Ga}\right] \mathrm{Ga}$-citrate came when Dr. Steven Larson conceptualized the gallium-transferrin conjugate as a ligand that binds to a tumor-associated transferrin receptor [16]. This understanding helps to explain the crucial importance of specific activity; when cold gallium is present, it competes to displace the labeled substrate from the transferrin receptor, thereby markedly changing the biodistribution. In much the same way, the transferrin hypothesis explains the curious relationship of $\left[{ }^{67} \mathrm{Ga}\right] \mathrm{Ga}$-citrate imaging and conditions causing iron overload, such as multiple transfusions, which also result in altered biodistribution [17]. Here too, the iron excess displaces gallium ions from the critical transferrin molecule, thereby decoupling the transferrin ligand from the radionuclide, which now behaves as an independent moiety. With respect to mechanism of uptake in infection, several possibilities have been postulated. These include regional hyperemia, increased vascular permeability and an expanded extracellular space, and the presence of gallium-avid proteins in the inflammatory exudate. Other implicated factors are the binding of gallium species in solution to leukocytes, bacteria, and their respective breakdown components of lactoferrin and siderophores $[18,19]$.

As an imaging radiopharmaceutical, $\left[{ }^{67} \mathrm{Ga}\right] \mathrm{Ga}$-citrate is hampered by several objective limitations including nonideal dosimetry, a prolonged delay between administration and imaging, suboptimal image quality, and a lack of specificity [20]. Nonetheless, $\left[{ }^{67} \mathrm{Ga}\right] \mathrm{Ga}$-citrate is still useful in a subgroup of cases of infection and inflammation, especially where $\left[{ }^{18} \mathrm{~F}\right] \mathrm{FDG}$ is not an option due to lack of availability or reimbursement. The Image of the Month by Zamora et al. [21] features an elderly woman who presented with evolving COVID-19-related lung infiltrates and presumed mastoiditis. Gallium scintigraphy was performed for the purpose of evaluating infection at the skull base. There was increased $\left[{ }^{67} \mathrm{Ga}\right] \mathrm{Ga}$-citrate uptake in the right mastoid, confirming active infection. In contrast, the confluent COVID-19-related parenchymal lung densities, which were included on the whole-body images and on the SPECT-CT field-of-view, did not take up more than minimal amounts of radiopharmaceutical. An additional tantalizing aspect of this case is the discrepancy between the minimal $\left[{ }^{67} \mathrm{Ga}\right] \mathrm{Ga}$-citrate uptake that we describe in the characteristic extensive lung infiltrates, and relatively intense $\left[{ }^{18} \mathrm{~F}\right] \mathrm{FDG}$ uptake which has been described in similar patients in a number of case reports [22-24]. A second patient with typical, though less extensive COVID19-related lung infiltrates, has also come to our attention and did not demonstrate significant gallium uptake, confirming our initial observation.
Large gaps exist in our understanding of the pathophysiology of COVD-19-related lung disease [25]. The disparity between reported $\left[{ }^{18} \mathrm{~F}\right] \mathrm{FDG}$ uptake and the lack of $\left[{ }^{67} \mathrm{Ga}\right] \mathrm{Ga}$-citrate uptake that we observed in COVID-19-related parenchymal lung densities certainly represents an enigma and may present medical researchers with some clues as to the nature of COVID-19 lung pathology. Mechanisms of $\left[{ }^{18} \mathrm{~F}\right] \mathrm{FDG}$ uptake are well understood and imply active transport of radiopharmaceutical via glucose transporters chiefly GLUT1 and GLUT3, as well as phosphorylation by hexokinase. These features are all prevalent in cells involved in infection and inflammation, especially neutrophils and the monocyte and macrophage family $[26,27]$. $\left[{ }^{67} \mathrm{Ga}\right]$ Ga-citrate uptake in inflammatory and infectious processes has been tied to several putative mechanisms we have discussed earlier, though the relative importance of each does not appear to be well-understood. The minimal uptake, observed in these two patients, does suggest absence of iron-binding receptors in the cellular response, which is hard to fathom because the same neutrophils and macrophages implicated in $\left[{ }^{18} \mathrm{~F}\right] \mathrm{FDG}$ uptake should be associated with gallium citrate binding. Post-mortem lung tissue obtained from patients infected with COVID-19 has shown damage to the lungs consistent with ARDS, focal necrosis, and lymphocytic and monocytic infiltration [28]. An intriguing though speculative theory to explain the paucity of $\left[{ }^{67} \mathrm{Ga}\right] \mathrm{Ga}$-citrate uptake is that the profound perturbations in iron-binding proteins associated with serious COVID-19 disease, evidenced by the markedly increased ferritin levels [29], may somehow interfere with the binding and metabolism of $\left[{ }^{67} \mathrm{Ga}\right] \mathrm{Ga}$-citrate. It is conceivable that the uptake at the site of mastoiditis may at least in part represent enhanced "bone tracer" effect of gallium ion when displaced from the transferrin molecule.

There is much to be learned from gallium's circuitous narrative, including the importance of serendipity in radiopharmaceutical development, the ability to think out-of-the-box and be receptive to trajectories that were not initially envisioned, and from a basic science point of view, the importance of specific activity on radiopharmaceutical biodistribution and the idea that the fate of a radiolabel may not always represent the behavior of the ligand. Lessons learned in the past will no doubt be relevant to applications in the future. It is interesting to speculate as to what chapters are yet to be written in the saga of gallium isotopes. Gallium-68, as the radiolabel of various somatostatin analogs, has made a great impact on the imaging of neuroendocrine tumors [30] and is being evaluated for labeling of PSMA-targeting compounds in the imaging of prostate cancer [31]. $\left[{ }^{68} \mathrm{Ga}\right] \mathrm{Ga}$-citrate has been developed as a substrate for PET-CT imaging in order to improve upon some of the limitations encountered when imaging $\left[{ }^{67} \mathrm{Ga}\right]$ Ga-citrate $[32,33]$. It is tempting to consider whether gallium radionuclides might possibly shed light on mechanisms of COVID-19-related lung disease or may somehow have useful application in the clinical evaluation of COVID-19 infection. 


\section{Compliance with ethical standards}

Conflict of interest The authors declare that they have no conflict of interest.

\section{References}

1. Hayes RL. The medical use of gallium radionuclides: a brief history with some comments. Semin Nucl Med. 1978;8(3):183-91.

2. Thakur ML. The radioactive compounds of gallium and indium. In: Rayudu GVS, editor. Radiotracers for medical applications. Boca Raton: CRC Press; 2019.

3. Dudley HC, Munn JI, Henry KE. Studies of the metabolism of gallium. II J Pharmacol Exp Ther. 1950;98(1):105-10.

4. Dudley HC, Marrer HH. Studies of the metabolism of gallium. III. Deposition in and clearance from bone. J Pharmacol Exp Ther. 1952;106(2):129-34.

5. Dudley HC, Imirie GW Jr, Istock JT. Deposition of radiogallium (Ga72) in proliferating tissues. Radiology. 1950;55(4):571-8. https://doi.org/10.1148/55.4.571.

6. Bruner HD, Perkinson JD, Jr, King ER, Andrews GA, Nash JB, Brucer M. V. Distribution studies on gallium in rats. Radiology. 1953;61(4):555-70.

7. Bruner HD, Hayes RL, Perkinson JD Jr. X. Preliminary data on gallium. Radiology. 1953;61(4):602-13.

8. Edwards CL, Hayes RL. Tumor scanning with $67 \mathrm{Ga}$ citrate. J Nucl Med. 1969;10(2):103-5.

9. Pinsky SM, Henkin RE. Gallium-67 tumor scanning. Semin Nucl Med. 1976;6(4):397-409.

10. Israel O, Keidar Z, Bar-Shalom R. Positron emission tomography in the evaluation of lymphoma. Semin Nucl Med. 2004;34(3):166-79.

11. Lavender JP, Lowe J, Barker JR, Burn JI, Chaudhri MA. Gallium 67 citrate scanning in neoplastic and inflammatory lesions. Br J Radiol. 1971;44(521):361-6.

12. Bell EG, O'Mara RE, Henry CA, Subramanian G, McAfee JG, Brown LC. Non-neoplasic localization of 67Ga-citrate. SNM Annual Meeting 1971. Appears in J Nucl Med. 12:338-9 19711971.

13. Littenberg RL, Taketa RM, Alazraki NP, Halpern SE, Ashburn WL. Gallium-67 for localization of septic lesions. Ann Intern Med. 1973;79(3):403-6. https://doi.org/10.7326/0003-4819-79-3403.

14. Bekerman C, Bitran J. Gallium-67 scanning in the clinical evaluation of human immunodeficiency virus infection: indications and limitations. Semin Nucl Med. 1988;18(4):273-86.

15. Palestro CJ. Molecular imaging of infection: the first 50 years. Semin Nucl Med. 2020;50(1):23-34. https://doi.org/10.1053/j. semnuclmed.2019.10.002.

16. Larson SM, Rasey JS, Allen DR, Nelson NJ, Grunbaum Z, Harp $\mathrm{GD}$, et al. Common pathway for tumor cell uptake of gallium-67 and iron-59 via a transferrin receptor. J Natl Cancer Inst. 1980;64(1):41-53.

17. Moreno AJ, Swaney JJ, Spicer MJ, Henry CD, Turnbull GL. The gallium-67 citrate bone scan. Clin Nucl Med. 1985;10(8):594-5.

18. Hoffer P. Gallium: mechanisms. J Nucl Med. 1980;21(3):282-5.
19. Tsan MF. Mechanism of gallium-67 accumulation in inflammatory lesions. J Nucl Med. 1985;26(1):88-92.

20. Palestro CJ, Love C. Nuclear medicine imaging in fever of unknown origin: the new paradigm. Curr Pharm Des. 2018;24(7): 814-20. https://doi.org/10.2174/1381612824666171129194507.

21. Zamora E, Valdivia AY, Zalta B, Zuckier LS. 67Ga-citrate and COVID-19-associated pneumonia: an unexpected absence of uptake. Eur J Nucl Med Mol Imaging. 2020. https://doi.org/10.1007/ s00259-020-04886-9.

22. Qin C, Liu F, Yen TC, Lan X. (18)F-FDG PET/CT findings of COVID-19: a series of four highly suspected cases. Eur J Nucl Med Mol Imaging. 2020;47(5):1281-6. https://doi.org/10.1007/ s00259-020-04734-w.

23. Zou S, Zhu X. FDG PET/CT of COVID-19. Radiology. 2020;200770. https://doi.org/10.1148/radiol.2020200770.

24. Setti L, Kirienko M, Dalto SC, Bonacina M, Bombardieri E. FDG$\mathrm{PET} / \mathrm{CT}$ findings highly suspicious for COVID-19 in an Italian case series of asymptomatic patients. Eur J Nucl Med Mol Imaging. 2020. https://doi.org/10.1007/s00259-020-04819-6.

25. $\mathrm{Xu} \mathrm{Z}$, Shi L, Wang Y, Zhang J, Huang L, Zhang C, et al. Pathological findings of COVID-19 associated with acute respiratory distress syndrome. Lancet Respir Med. 2020;8(4):420-2. https://doi.org/10.1016/S2213-2600(20)30076-X.

26. Arnon-Sheleg E, Israel O, Keidar Z. PET/CT imaging in soft tissue infection and inflammation-an update. Semin Nucl Med. 2020;50(1):35-49. https://doi.org/10.1053/j.semnuclmed.2019.07. 005 .

27. Mochizuki T, Tsukamoto E, Kuge Y, Kanegae K, Zhao S, Hikosaka K, et al. FDG uptake and glucose transporter subtype expressions in experimental tumor and inflammation models. $\mathrm{J}$ Nucl Med. 2001;42(10):1551-5.

28. Merad M, Martin JC. Pathological inflammation in patients with COVID-19: a key role for monocytes and macrophages. Nat Rev Immunol. 2020. https://doi.org/10.1038/s41577-020-0331-4.

29. Colafrancesco S, Alessandri C, Conti F, Priori R. COVID-19 gone bad: a new character in the spectrum of the hyperferritinemic syndrome? Autoimmun Rev. 2020. https://doi.org/10.1016/j.autrev. 2020.102573.

30. Kulkarni HR, Singh A, Baum RP. Advances in the diagnosis of neuroendocrine neoplasms. Semin Nucl Med. 2016;46(5):395404. https://doi.org/10.1053/j.semnuclmed.2016.06.001.

31. Sheikhbahaei S, Werner RA, Solnes LB, Pienta KJ, Pomper MG, Gorin MA, et al. Prostate-specific membrane antigen (PSMA)targeted PET imaging of prostate cancer: an update on important pitfalls. Semin Nucl Med. 2019;49(4):255-70. https://doi.org/10. 1053/j.semnuclmed.2019.02.006.

32. Vorster M, Maes A, Wiele C, Sathekge M. Gallium-68 PET: a powerful generator-based alternative to infection and inflammation imaging. Semin Nucl Med. 2016;46(5):436-47. https://doi.org/10. 1053/j.semnuclmed.2016.04.005.

33. Segard T, Morandeau L, Dunne ML, Robinson JO, Murray RJ, Geelhoed EA, et al. Comparison between gallium- 68 citrate positron emission tomography-computed tomography and gallium-67 citrate scintigraphy for infection imaging. Intern Med J. 2019;49(8): 1016-22. https://doi.org/10.1111/imj.14231.

Publisher's note Springer Nature remains neutral with regard to jurisdictional claims in published maps and institutional affiliations. 